\title{
PRINCÍPIO DA SELETIVIDADE PELAS BALIZAS DA TRIBUTAÇÃO AMBIENTAL: IPI e ICMS
}

PRINCIPLE OF SELECTIVITY FOR ENVIRONMENTAL GOALS OF TAXATION: IPI and ICMS

Gabriel Antônio de Moraes Vieira*

Submissão: 09/06/2013 Aceito para Publicação: 14/08/2013

Sumário: 1. Introdução. 2. Uma nova preocupação global: o meio ambiente. 3. Finalidade da tributação ambiental: fiscal ou extrafiscal. 3.1. Princípio da seletividade. 4. A tributação ambiental no direito comparado. 5. A tributação ambiental no brasil. 5.1. IPI. 5.2. ICMS. 5.3. ICMS ecológico. 6. Proposta valorativa da tributação ambiental. 7. Considerações finais. Referências.

Resumo: O presente artigo objetiva a análise da evolução da tutela ambiental no Direito Brasileiro e no Exterior, buscando, através do Direito Tributário, meios para auxiliar na concretização da garantia constitucional de um meio ambiente ecologicamente equilibrado. Abordar-se-ão aspectos da extrafiscalidade tributária, bem como da aplicação do princípio da seletividade. Ademais, o trabalho visará a encontrar, no IPI e no ICMS, meios para contribuir na concretização de um meio ambiente sustentável. Finalizando o presente trabalho, proporse-á uma nova visão acerca da aplicação do princípio da seletividade, em especial aos tributos referidos, buscando a essencialidade de um meio ambiente saudável, como parâmetros para sua aplicação.

\footnotetext{
* Pontifícia Universidade Católica do Rio Grande do Sul.
} 
Palavras-chave: Direito Tributário Ambiental; Extrafiscalidade; Princípio da seletividade; IPI; ICMS.

Abstract: This article aims to analyze the evolution of environmental protection in Brazilian Law and abroad, seeking, through Tax Law, means to assist in the implementation of the constitutional guarantee of an ecologically balanced environment. It shall be addressed nonfiscal aspects of tax, as well as the principle of selectivity. Moreover, the paper will aim to find, in the IPI and ICMS, means to contribute to the achievement of a sustainable environment. Concluding this paper, it will be proposed a new view on the implementation of the principle of selectivity, especially on the mentioned taxes, seeking the essentiality of a healthy environment as parameters for its application.

Keywords: Environmental Tax Law; Non-fiscal aspects; Principle of selectivity; IPI; ICMS.

\section{INTRODUÇÃO}

Notório é que, nos dias atuais, o mundo vive um momento de convergência em prol do meio ambiente e da saúde do planeta. Nessa seara, surgiu o presente trabalho, que objetiva a busca, no Direito Tributário, de meios para concretizar valores básicos, como a obtenção de um meio ambiente ecologicamente equilibrado.

O progresso é importante para a humanidade, no entanto o processo de desenvolvimento econômico deve ter compromisso com a proteção ambiental. ${ }^{1}$

Assim, o presente trabalho fará uma busca histórica acerca da origem e da evolução da preocupação global com o meio ambiente, verificando como se situa no ordenamento jurídico interno e como o Direito Tributário pode ser utilizado para concretizar os fins ecológicos.

Ainda, far-se-á a verificação de como a matéria é abordada no Direito Comparado, principalmente acerca da finalidade dos tributos utilizados, se fiscais ou extrafiscais. Posto isto, conceituar-se-ão tais finalidades e se buscará fazer uma avaliação relativa às possibilidades de sua utilização como modo de garantir um meio ambiente sustentável.

\footnotetext{
1 TEIXEIRA, Dalvio Leite Dias; TEIXEIRA, Silvia Maria Benedetti. A constitucionalidade da tributação ambiental no Brasil. Revista da AJURIS, Associação dos Juízes do Rio Grande do Sul, Porto Alegre, v. 36, n. 115, p. 78, set. 2009.
} 
Ademais, buscar-se-á realizar análise quanto ao princípio da seletividade e de como o mesmo se comporta no ordenamento jurídico interno, principalmente no que diz respeito aos impostos sobre produtos industrializados e sobre a circulação de mercadorias e serviços, que também serão observados e analisados.

E, por fim, propor-se-á uma união entre os interesses ambientais e o Direito Tributário, verificando-se, assim, a possibilidade de, através do princípio da seletividade, contribuir para a busca por um “planeta saudável”.

\section{UMA NOVA PREOCUPAÇÃO GLOBAL: O MEIO AMBIENTE}

Inegavelmente, nas últimas décadas, houve relevante crescimento da população mundial. Inerente a tal acréscimo, veio o desenvolvimento dos setores da indústria e do comércio, uma vez que, com o acréscimo populacional e uma distribuição de riquezas igualitária, a sociedade passou a ter maiores oportunidades para a aquisição de bens e serviços antes inimagináveis. ${ }^{2}$

Entretanto, a busca desenfreada por riquezas, consumo, facilidades e conforto fez com que as comunidades emergissem em séria crise de percepção que tem levado o planeta a

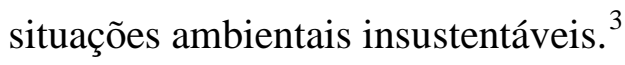

Dessa forma, após período de intenso desenvolvimento, bem como a utilização incessante dos recursos naturais, a preocupação ambiental emergiu, mobilizando toda a humanidade. ${ }^{4}$ Em virtude de tamanha agressão à natureza, os ecologistas impulsionaram relevantes movimentos sociais de proteção ao meio ambiente, os quais, inevitavelmente, acabaram desembocando nas ciências jurídicas. ${ }^{5}$

O primeiro passo foi dado com a elaboração da Declaração sobre o Meio Ambiente Humano, realizada em 1992 na Conferência das Nações Unidas para o Meio Ambiente, na cidade de Estocolmo, na Suécia. Esta foi a primeira manifestação coletiva de Estados acerca

\footnotetext{
2 RODRIGUEIRO, Daniela A; SOUZA, Luiz Gustavo Alves de. Do caos à consciência ecológica: breves reflexões sobre degradação e preservação ambiental. Revista do Instituto de Pesquisas e Estudos, Bauru, Divisão Jurídica, n. 48, p. 337, jul. 2007.

${ }^{3}$ RODRIGUEIRO, Daniela A; SOUZA, Luiz Gustavo Alves de. Op. cit. p. 337.

${ }^{4}$ ABREU, Rafaela Franco. A tributação ambiental no Brasil e nos Estados Unidos - Uma análise comparativa. Publicações da Escola da AGU, Brasília, v. 4, n. 16, p. 235, mar. 2012.

${ }^{5}$ RODRIGUEIRO, Daniela A; SOUZA, Luiz Gustavo Alves de. Op. cit. p. 342.
} 
da questão ambiental planetária, momento em que restou formado um órgão para democratizar o sistema internacional de decisões sobre o meio ambiente. ${ }^{6}$

Desde então, a preocupação com o meio ambiente somente se intensificou, e, após a conferência sueca, houve grande número de eventos sobre o tema, entretanto alguns deles tiveram grande relevância, como, por exemplo, a ECO-92, realizada na cidade do Rio de Janeiro, no Brasil, e a RIO + 10, ocorrida em Johannesburgo, na África do Sul.

Portanto, com escassos exemplos, percebe-se que o mundo está cada vez mais voltado para o meio ambiente, evoluindo a cada ano e a cada evento, mas, ainda, de maneira muito vagarosa.

Por fim, importa ressaltar que a Constituição Federal brasileira não se furtou de tal tema, deixando cristalina sua preocupação com a proteção ambiental, uma vez que passou a considerá-la como direito da pessoa humana. Para tanto, positivou tais garantias em seus artigos $170, \mathrm{VI}^{7}$, e $225^{8}$.

Destarte, tendo em vista a preocupação instigada pelo desgaste ambiental, bem como a função social do Direito Tributário, estudar-se-á como tal ramo do Direito poderá contribuir para o alcance de um meio ambiente ecologicamente equilibrado.

\section{FINALIDADE DA TRIBUTAÇÃO AMBIENTAL: FISCAL OU EXTRAFISCAL}

Notório é que os tributos, de um modo geral, são entendidos como instrumentos de fiscalidade, sendo utilizados para carrear dinheiro aos cofres públicos. ${ }^{9}$ Entretanto, modernamente, vem se agregando uma nova finalidade à tributação: a extrafiscalidade. ${ }^{10}$

Segundo a primeira finalidade, a tributação possui como escopo a arrecadação de verbas para os cofres públicos, objetivando regular o funcionamento do Estado. Já na segunda função - extrafiscal - o tributo não visa à arrecadação, mas sim ao exercício de atividade

\footnotetext{
${ }^{6}$ Ibidem, p. 342-343.

${ }^{7} \mathrm{O}$ inciso IV assim leciona: “defesa do meio ambiente, inclusive mediante tratamento diferenciado conforme o impacto ambiental dos produtos e serviços e de seus processos de elaboração e prestação;” BRASIL. Constituição da República Federativa do Brasil de 1988. Disponível em: <http://www.planalto.gov.br/ccivil_03/constituicao/constituicao.htm>. Acesso em: 1. ${ }^{o}$ jun. 2013

${ }^{8}$ O referido dispositivo constitucional assim determina: “Art. 225. Todos têm direito ao meio ambiente ecologicamente equilibrado, bem de uso comum do povo e essencial à sadia qualidade de vida, impondo-se ao Poder Público e à coletividade o dever de defendê-lo e preservá-lo para as presentes e futuras gerações.”

${ }^{9}$ CARRAZZA, Roque Antônio; BOTTALLO, Eduardo Domingos. IPI, seletividade e alteração de alíquotas. Revista Dialética de Direito Tributário, São Paulo, RDDT, n. 159, p. 107, dez. 2008.

${ }^{10}$ DIFINI, Luiz Felipe Silveira. Manual de Direito Tributário. 4 ed. atual. São Paulo: Saraiva, 2008. p. 17.
} 
regulatória, utilizando o estímulo (ou o desestímulo) de determinadas atividades como forma de intervenção do Poder Público no domínio econômico. ${ }^{11}$

Quanto à tributação ambiental, observar-se-á que ambas as finalidades estão presentes, no entanto tal ocorrência não se manifesta em proporções de igualdade, mas com a prevalência da função extrafiscal sobre a fiscal.

Tal fato ocorre porque, mais do que uma atitude isolada, a extrafiscalidade tributária é meio de tributação em prol da coletividade. Aumentam-se ou reduzem-se alíquotas com o intuito de induzir os contribuintes a fazer ou deixar de fazer alguma coisa. ${ }^{12}$

Paulo Henrique do Amaral muito bem aponta que o caráter extrafiscal prevalece na tributação ambiental, pois seu escopo é estimular condutas não poluidoras e coibir as agressoras ao meio ambiente, ficando a natureza arrecadatória em plano secundário. ${ }^{13}$

Pode-se considerar que a defesa de um meio ambiente sadio é exemplo cristalino de defesa dos interesses difusos. Na busca por sua proteção, o Direito Tributário conta com a extrafiscalidade, podendo transformar as diversas atividades do Direito em instrumentos que promovam atividades econômicas ambientalmente sustentáveis. ${ }^{14}$

Nessa seara, observa-se que o Direito Tributário deve ser entendido não somente como área para a arrecadação e custeio dos gastos do Estado, mas, principalmente, como meio de defesa dos interesses da sociedade, entre eles um meio ambiente sustentável. ${ }^{15}$

Em análise da extrafiscalidade nos tributos ambientais, adere-se à tese apresentada por Caliendo, que aponta para a existência de três diretrizes: $1^{\mathrm{a}}$ ) tratamento diferenciado às atividades poluidoras, considerando-se substantiva diferença entre estas e as demais atividades econômicas, uma vez que se trata de justiça distributiva; $2^{\mathrm{a}}$ ) tratamento adequado visando ao bem comum, correlacionando o interesse privado e a sua contribuição para a manutenção de uma sociedade ambientalmente saudável; e $3^{\mathrm{a}}$ ) sanção em caso de desequilíbrio gerado pela conduta poluidora. ${ }^{16}$

Em suma, o doutrinador demonstra que a extrafiscalidade poderá se relacionar com o Direito Tributário de maneira direta, indireta ou repressiva. No primeiro caso, há uma

\footnotetext{
${ }^{11}$ Ibidem, p. 17.

${ }^{12}$ CARRAZZA, Roque Antonio. Curso de Direito Constitucional Tributário. 22 ed. São Paulo: Malheiros, 2006. p. 107-108.

${ }^{13}$ AMARAL, Paulo Henrique. Direito Tributário Ambiental. São Paulo: Revista dos Tribunais, 2007. p. 64.

${ }^{14}$ VIEIRA, Andréia Costa. O direito humano ao meio ambiente e a tributação ambiental: água e ar: mecanismos nacionais e internacionais. Fórum de Direito Urbano e Ambiental, Belo Horizonte, v. 9, n. 53, p. 18-19, set. /out. 2010.

${ }^{15}$ VIEIRA, Andréia Costa. Op. cit. p. 18-26.

16 CALIENDO, Paulo. Tributação e mercado de carbono. In: TORRES, Heleno Taveira (Org.). Direito Tributário Ambiental. São Paulo: Malheiros, 2005. p. 876.
} 
preocupação de onerar aquelas atividades prejudiciais ao meio ambiente. Já na tributação indireta, o Estado se utiliza da tributação como meio de defesa àquelas atividades cuidadosas com a sustentabilidade, seja através da redução de alíquotas, seja por concessão de benefícios e isenções. E, por fim, surge a modalidade repressiva, a qual visa a reparar os danos já causados ao meio ambiente.

Menciona-se não seria mais adequado que o presente artigo ater-se-á tão somente às duas primeiras modalidades, uma vez que as atividades repressivas, por serem exemplos claros de sanção por ato ilícito, não são consideradas tributo pelo ordenamento jurídico pátrio, conforme ensina o artigo $3 .^{\circ}$ do Código Tributário Nacional. ${ }^{17}$

\subsection{Princípio da Seletividade}

Conforme entendimento de Luiz Felipe Silveira Difini, o princípio da seletividade é modo de adequação do princípio da capacidade contributiva. Para o doutrinador, a seletividade "significa taxar com alíquotas mais altas os produtos de consumo supérfluo ou não essencial e de forma reduzida aqueles produtos tidos como essenciais ao consumo da população, especialmente aquela de menor capacidade econômica”. ${ }^{18}$

Observa-se que o intuito da aplicação do princípio da seletividade é adequar os produtos à vida do maior número de habitantes do país. Com isso, as mercadorias essenciais serão tratadas com favorecimento tributário e ofertadas ao maior número de pessoas. Já as mercadorias consideradas supérfluas devem ser taxadas com maior rigor, uma vez que não se trata de bens inerentes à sobrevivência e ao bem-estar humano. ${ }^{19}$

Cumpre referir que a Constituição Federal não aponta quais os produtos, mercadorias ou serviços são essenciais à sociedade, no entanto pode-se considerar como essenciais aqueles produtos consumidos por toda a população. ${ }^{20}$ Já os supérfluos são consumidos somente por aquelas pessoas que, já tendo satisfeitas as suas necessidades básicas, possuem recursos para suprir outros custos. ${ }^{21}$

\footnotetext{
${ }^{17} \mathrm{O}$ referido dispositivo assim leciona: “Art. 3. ${ }^{\circ}$ Tributo é toda prestação pecuniária compulsória, em moeda ou cujo valor nela se possa exprimir, que não constitua sanção de ato ilícito, instituída em lei e cobrada mediante atividade administrativa plenamente vinculada”. BRASIL. Código Tributário Nacional. Disponível em: $<$ http://www.planalto.gov.br/ccivil_03/leis/15172.htm>. Acesso em: 2 jun. 2013.

${ }^{18}$ DIFINI, Luiz Felipe Silveira. Op. cit. p. 90.

${ }^{19}$ BALEEIRO, Aliomar. Direito Tributário Brasileiro. 7 ed. Rio de Janeiro: Forense, 1975. p. 188.

${ }^{20}$ DANILEVICZ, Rosane Beatriz Jachimovski. O princípio da essencialidade na tributação. Direito tributário em questão. Revista da FESDT, Porto Alegre, v. 2, n. 3, p. 242, jan./jun. 2009.

${ }^{21}$ PAULSEN, Leandro; MELO. José Eduardo Soares de. Impostos federais, estaduais e municipais. 4 ed. rev. e atual. Porto Alegre: Livraria do Advogado, 2008. p. 264.
} 
Importa ressaltar que, muitas vezes, são considerados como produtos de primeira necessidade somente aqueles como alimentação, vestuário, medicamentos e outros. No entanto, conforme muito bem exposto por Bottallo, o alcance do princípio da seletividade não se esgota nisto. ${ }^{22}$

Para o autor, todos aqueles produtos afinados com a proteção ambiental devem ser tributados minimamente, ou não tributados. Assim, colocar-se-iam sob a salvaguarda da seletividade os produtos por ele denominados de "ecologicamente corretos", expressão adotada com euforia no presente trabalho.

Infere ressaltar que a aplicação da seletividade se dá em virtude da necessidade, fator de regulação do mínimo existencial. Visa, portanto, a garantir à humanidade os meios mínimos para uma existência saudável, contribuindo, assim, para a efetividade do princípio da dignidade humana.

Na tributação ambiental, busca-se claramente a defesa de um meio ambiente saudável à sociedade, ou seja, uma vida com qualidade. Desta forma, a seletividade realizaria a concretização dos referidos objetivos de maneira inigualável, uma porque oneraria aqueles contribuintes poluidores e, de maneira proporcional, beneficiaria os preocupados com a saúde ambiental.

\section{A TRIBUTAÇÃO AMBIENTAL NO DIREITO COMPARADO}

Anteriormente à análise da tributação ambiental no ordenamento jurídico-tributário brasileiro, buscar-se-á realizar breves considerações acerca de como a matéria é tratada no Direito Comparado.

Considerado como um dos países mais preocupados com a defesa do meio ambiente, a Suécia apresenta diversos exemplos de tributação ambiental.

Sinteticamente, cumpre apontar os itens de maior relevo na legislação daquele país. Desde 1991, a Suécia conta com impostos sobre óxidos de carbono, onerando as empresas pelo conteúdo dos gases emitidos pela queima de combustíveis conforme o tipo: petróleo, carvão, gás natural, gás liquefeito e gasolina; e sobre o dióxido de enxofre incidente sobre a emissão desse gás, aferido diretamente nas grandes instalações industriais. ${ }^{23}$

\footnotetext{
${ }^{22}$ BOTTALLO, Eduardo Domingos. IPI: princípios e estrutura. São Paulo: Dialética, 2009. p. 54-55.

${ }^{23}$ GUSMÃO, Omara Oliveira de. Proteção ambiental e tributação: O tributo como coadjuvante na concretização do valor constitucional “meio ambiente”. Revista Tributária e de Finanças Públicas, São Paulo, Revista dos Tribunais, n. 66, p. 118, jan/fev, 2006.
} 
Ainda, de maneira exemplar, a legislação sueca prevê a devolução, total ou parcial, dos valores pagos se as empresas efetuarem a instalação de filtros ou outros mecanismos para a redução ou a eliminação dos gases prejudiciais lançados no ambiente. Por fim, insta mencionar que, naquele ordenamento jurídico, também há a imposição de tributos sobre o consumo de energia e de poluição do meio ambiente dos veículos, bem como alguns produtos passaram a ser tributados conforme as respectivas características poluentes. ${ }^{24}$

Destarte, observa-se a completude do Direito Tributário sueco, que, além de demonstrar a preocupação em taxar ferozmente os poluidores, busca favorecer os contribuintes preocupados com o meio ambiente, seja utilizando produtos ecologicamente corretos, seja utilizando-se de meios para a redução ou a eliminação da emissão de poluentes na natureza.

Em Portugal, conforme aponta Nabais, há três áreas de pesquisas jurídicas acerca do meio ambiente: 1) responsabilidade civil por danos ambientais; 2) subsídios e subvenções do Direito Financeiro; e 3) os impostos ambientais e os benefícios fiscais ambientais do Direito Fiscal. $^{25}$

No presente estudo, analisar-se-á tão somente o terceiro ponto, ou seja, a defesa do meio ambiente pela tributação.

Para o autor, os impostos contribuem muito pouco para a evolução ecológica de Portugal. Nabais considera que os benefícios ofertados aos bons contribuintes são os que realizam de forma mais efetiva a preservação ambiental.

No Direito espanhol, a tributação ambiental possui finalidade fundamentalmente extrafiscal, sendo regida pelo princípio “quien contamina, paga”, modalidade específica do princípio da equivalência, que determina que tanto aquele que contaminou quanto aqueles que utilizarem o meio ambiente para lucrar deverão custear a sua utilização. Isto se dá pelo fato de que ninguém poderá lucrar à custa da sociedade. ${ }^{26}$

Ainda, quanto ao tema, cumpre ressaltar as considerações de Domingo Vasco e Pedro Herrera Molina, para quem os tributos somente têm autêntica natureza ambiental quando os

\footnotetext{
${ }^{24}$ Ibidem, p. 118.

25 NABAIS, José Casalta. Direito Fiscal e Tutela do Ambiente em Portugal. In: TORRES, Heleno Taveira (Org.). Direito Tributário Ambiental. São Paulo: Malheiros, 2005. p. 412-422.

${ }^{26}$ TABOADA, Carlos Paolo. El principio “quien contamina paga” y el principio de capacidad econômica. In: TORRES, Heleno Taveira (Org.). Direito Tributário Ambiental. São Paulo: Malheiros, 2005. p. 79-82.
} 
desenhos de seus elementos quantitativos constituam um incentivo para a proteção do meio ambiente. $^{27}$

No Direito norte-americano, diversas são as disposições legais tributárias voltadas para a proteção ambiental. Pode-se apontar a existência do adicional “ambiental” do imposto de renda; a dedutibilidade de doações de terrenos e matas com finalidade preservacionistas; o imposto pago pelos refinadores sobre petróleo e derivados e, ainda, o imposto devido pelas empresas químicas sobre produtos químicos perigosos e derivados. ${ }^{28}$

Outra medida adotada é a imposição de sobretaxa no preço dos produtos potencialmente poluentes, tais como vasilhames de bebidas, pneus e baterias de automóveis. ${ }^{29}$

Na Alemanha, há a adoção, por meio de impostos, de incentivos à produção de veículos com menor cilindrada, catalisadores e gasolina sem plomo (chumbo). ${ }^{30}$ Ainda, há imposto municipal sobre embalagens, pratos e talheres descartáveis e a tributação maior sobre veículos não guarnecidos de catalisadores. ${ }^{31}$

Destarte, nota-se que o mundo busca, incessantemente, meios para que o progresso venha acompanhado de preocupações básicas para a manutenção de uma vida saudável à humanidade. Uma destas formas foi onerar aquelas entidades que contribuem para o desgaste do meio ambiente, favorecendo, por outro lado, as que assiduamente desenvolvem meios ecologicamente corretos para realizar suas atividades.

Por conseguinte, percebe-se flagrante a finalidade extrafiscal da tributação no Direito Comparado, a qual é aplicada por meio da seletividade “ecológica” de produtos, mercadorias e serviços prestados. ${ }^{32}$

\section{A TRIBUTAÇÃO AMBIENTAL NO BRASIL}

Em virtude da intensa degradação ambiental, não foi outra a consequência senão a criação de novo ramo do Direito Tributário, denominado Direito Tributário Ambiental.

O professor Heleno Torres, em obra acerca do tema, muito bem definiu esta nova área de pesquisa, considerando-a como:

\footnotetext{
27 CARBAJO VASCO, Domingo; HERRERA MOLINA, Pedro M. Marco conceptual, constitucional y comunitario de la fiscalidad ecologica. Revista de Direito Tributário, São Paulo, Malheiros, v. 89, p. 121-123, 2003.

${ }^{28}$ COSTA, Regina Helena. Tributação ambiental. In: FREITAS, Vladimir Passos de (Coord.). Direito ambiental em evolução. Curitiba: Juruá, 1998. p. 298-301. v. 1.

${ }^{29}$ ABREU, Rafaela Franco. Op. cit. p. 246-247.

${ }^{30}$ GUSMÃO, Omara Oliveira de. Op. cit. p. 119.

${ }^{31}$ COSTA, Regina Helena. Op. cit. p. 300.

32 Cumpre apontar que a locução “ecológica”, no presente trabalho, será utilizada tanto em relação à sustentabilidade ambiental, como referente a baliza necessária à aplicação do princípio da seletividade.
} 
Ramo da ciência do direito tributário que tem por objetivo o estudo das normas jurídicas tributárias elaboradas em concurso com o exercício de competências ambientais, para determinar o uso de tributo na função instrumental de garantia ou preservação de bens ambientais. ${ }^{33}$

Pode-se concluir que a nova linha de pensamento e preocupações do Direito Tributário se coaduna perfeitamente com a tese defendida por Alfredo Augusto Becker, que prega a necessidade de um Direito Tributário dinâmico e inovador que se comprometesse, cada vez mais, com os anseios da humanidade. ${ }^{34}$

A tributação ambiental pode ser singelamente conceituada como o emprego de instrumentos tributários para orientar o comportamento dos contribuintes, bem como para gerar os recursos necessários à prestação de serviços públicos de natureza ambiental. ${ }^{35}$

Isto posto, levando em conta que a proteção do meio ambiente e a promoção da qualidade de vida da sociedade são elementos fundamentais do princípio da dignidade da pessoa humana, reconhecidos constitucionalmente no ordenamento jurídico brasileiro, surgiu a possibilidade de utilizar o sistema tributário nacional como mecanismo para sua concretização. ${ }^{36}$

Desta forma, passou-se a pensar e estudar de que maneira os tributos poderiam contribuir para a realização dos direitos das pessoas a um meio ambiente ecologicamente equilibrado.

Observa-se que, até a presente data, não há no Direito brasileiro legislação específica acerca da matéria, no entanto alguns movimentos vêm surgindo com esta finalidade.

Nesta seara, busca-se, por meio do presente trabalho, contribuir para o desenvolvimento da matéria. Para tanto, serão abordados aqueles impostos em que, teoricamente, há repasse do ônus financeiro ao consumidor final, haja vista a não cumulatividade que lhes é inerente (IPI e ICMS). ${ }^{37}$

Portanto, passar-se-á à análise ecológica dos referidos tributos.

\footnotetext{
${ }^{33}$ TORRES, Heleno Taveira (Org.). Direito Tributário Ambiental. São Paulo: Malheiros, 2005. p. 101-102.

${ }^{34}$ BECKER, Alfredo Augusto. Teoria Geral do Direito Tributário. 2 ed. São Paulo: Saraiva, 1972. p. 553.

${ }^{35}$ COSTA, Regina Helena Op. cit. p. 297.

36 ARAÚJO, Luiz Ernani Bonesso de; BARICHELLO, Stefania Eugenia; TEIXEIRA, Michele Oliveira. Tributação ambiental: considerações sobre o ICMS ecológico e alguns tributos verdes de países desenvolvidos. Revista da Procuradoria-Geral do Estado, Porto Alegre, v. 31, n. 66, p. 136, jul./dez. 2007.

${ }^{37}$ Difini alerta para a precariedade da distinção dos tributos em diretos e indiretos, considerando que a repercussão econômica pode ocorrer independente do tributo. Para o autor, até mesmo o IRPJ poderia ser repassado ao consumidor, bastando uma elevação do preço do produto até o ponto de cobrir os valores devidos pela tributação. DIFINI, Luiz Felipe Silveira. Op. cit. p. 29-30.
} 


\subsection{IPI}

Conforme muito bem exposto por Roque Carrazza e Eduardo Bottallo, o Imposto sobre Produtos Industrializados (IPI) é tributo que deve ser utilizado como instrumento de ordenação político-econômica. ${ }^{38} \mathrm{O}$ referido tributo possui como escopo estimular as práticas tidas como necessárias e convenientes à sociedade e, em contrapartida, onerar as que não atendam ao interesse social. ${ }^{39}$

Esta característica do IPI, eminentemente extrafiscal, restou materializada com a positivação, na Constituição Federal, do princípio da seletividade, presente no artigo 153, § $3^{\circ}$, I, que determina que a alíquota do IPI será seletiva em razão da essencialidade do produto. $^{40}$

Observa-se, assim, que o legislador constituinte determinou que o tributo - que ora se estuda - deverá, obrigatoriamente, observar a essencialidade do bem para fins de tributação. Ainda, conforme já exposto, a essencialidade é aquela que atende aos interesses sociais, regulando o princípio do mínimo existencial.

Esta imposição constitucional significa que o legislador, ao estabelecer as alíquotas e a forma de tributação do IPI, não poderá incluir em seu rol os produtos industrializados que sejam artigos de primeira necessidade à população. Portanto, aqueles produtos considerados populares e convenientes ao povo não deverão ser tributados pelo referido imposto. ${ }^{41}$

Assim, observando-se a necessidade popular de um meio ambiente ecologicamente equilibrado, bem como a obrigatoriedade de observação, por parte do IPI, à essencialidade dos bens tributados, conclui-se que aqueles produtos que contribuírem para a manutenção de um meio ambiente saudável devem ser observados e valorizados pelo legislador.

Que há a aplicação do princípio da seletividade ao IPI, isto é notório, basta verificar que, para produtos básicos, tais como alimentos, a alíquota é relevantemente baixa, ou até zerada, enquanto nos casos de produtos considerados supérfluos, como bebidas e cigarros, as alíquotas são fortemente elevadas (sobre a vodca incide uma alíquota de $60 \%$, enquanto sobre os cigarros ela é de $300 \%){ }^{42}$

\footnotetext{
${ }^{38}$ CARRAZZA, Roque Antônio; BOTTALLO, Eduardo Domingos. Op. cit. p. 107.

39 CARRAZZA, Roque Antonio. Curso de Direito Constitucional Tributário. 24. ed. São Paulo: Malheiros, 2006. p. 97.

${ }^{40}$ O referido dispositivo assim leciona: “I - será seletivo, em função da essencialidade do produto;”

${ }^{41}$ NOGUEIRA, Ruy Barbosa. Principio da seletividade do tributo em função da essencialidade do produto. São Paulo: Revista dos Tribunais, 1990. p. 10. v. 651.

${ }^{42}$ Vide Tabela de Incidência do IPI. Anexo Único do Decreto n. ${ }^{\circ}$ 7.660, de 23 de dezembro de 2011.
} 
No entanto, o que se busca não é o emprego da necessidade como parâmetro único da tributação do IPI, mas também utilizar a sustentabilidade como baliza para a definição de alíquotas e bases de cálculo.

Bom exemplo quanto ao tema é o Decreto Federal n. ${ }^{\circ} 755 / 93$, que estabelece diferentes alíquotas do IPI para veículos movidos a gasolina (25 ou 30\%) e para veículos movidos a álcool (20 ou 25\%). ${ }^{43}$ No entanto, imprescindível é apontar que a finalidade do referido diploma legal, à época, não era a preservação ambiental, mas sim o incentivo à produção de veículos movidos a álcool, diminuindo, assim, a importação de petróleo. ${ }^{44}$

Entretanto, muito embora não tenha havido o pensamento em prol do ambiente, a criação do decreto pode ser considerada um grande passo para preservação da natureza.

Exemplo prático acerca dos problemas existentes na tributação do IPI pode ser dado quando se fala do transporte de pessoas. Conforme disposto no item 8703.21.00 da Tabela de Incidência do IPI (TIPI), os veículos automotores de transporte de até seis passageiros, de cilindrada não superior a $1.000 \mathrm{~cm}^{3}$, são tributados com alíquota de $7 \%$. Já sobre os veículos em iguais condições, mas com cilindrada entre 1.000 a $1.500 \mathrm{~cm}^{3}$, a alíquota do IPI chega a 13\%. Aparentemente, pode-se pensar que o tributo está cumprindo sua função ambiental, uma vez que onera o veículo mais poluente. No entanto, o mesmo pensamento não prevalece quando analisado o item 8712.00.10 da referida tabela, que tributa as bicicletas com alíquota de $10 \%$.

Consequentemente, observa-se, no caso em tela, que há clara preferência do legislador em tributar brandamente os veículos, desfavorecendo as bicicletas. No entanto, cumpre lembrar que estas são meios de transporte totalmente limpos, ou seja, não agridem, de maneira alguma, o meio ambiente. Já os primeiros são constantes emissores de gases tóxicos e poluentes no ar.

Destarte, tem-se como necessária a adoção de critérios ambientais para valoração da seletividade, tributando com maior voracidade aqueles produtos poluidores e brandamente aqueles ecologicamente corretos. Nestes termos, em observância aos princípios do mínimo existencial e da seletividade, pode-se afirmar que estes últimos possuem amplo respaldo para ser contemplados com alíquotas diferencialmente reduzidas, ou, se possível, zeradas.

\footnotetext{
43 BRASIL. Decreto Federal n. ${ }^{\circ}$ 755/93, de 19 de fevereiro de 1993. Reduz as alíquotas do Imposto sobre Produtos Industrializados incidente sobre os veículos automotores que enumera. Diário Oficial da União, Brasília, 20 fev. 1993, p. 2272.

${ }^{44}$ COSTA, Regina Helena. Op. cit. p. 301-302.
} 


\subsection{ICMS}

Ao estudar as normas do Imposto sobre Circulação de Mercadorias e Serviços (ICMS), que também incide sobre as prestações de serviços de transporte interestadual, intermunicipal e de comunicação, observa-se a existência do princípio da seletividade, entretanto de maneira diversa daquela estudada no imposto sobre produtos industrializados.

Conforme leciona o artigo 155, § 2. ${ }^{\circ}$, III, da Constituição Federal, o ICMS poderá ser seletivo em função da essencialidade das mercadorias e dos serviços. ${ }^{45}$ Desta forma, ao disciplinar a utilização do tributo supracitado, o legislador apontou que o mesmo poderá ser seletivo, e não deverá ser, como ocorre no caso do IPI.

Deste modo, pela literalidade do dispositivo legal, chega-se à conclusão de que, no caso do ICMS, não há a obrigatoriedade de o ente tributante observar a essencialidade do bem para fixar suas alíquotas, mas deverá fazê-lo.

Nesses termos, cumpre apresentar o magistério de Leandro Paulsen e José Eduardo Soares de Melo, que alertam para a utilização arbitrária da facultatividade da observância da seletividade nos casos do ICMS. ${ }^{46}$ Para os autores, muito embora seja opcional a aplicação do princípio a esses casos, não se justificariam consideráveis elevações de alíquota nos casos de produtos de primeira necessidade, com a simplória justificativa de necessidade de arrecadação.

Observa-se que a facultatividade apresentada oportunizou uma maior flexibilidade ao legislador, no entanto não lhe transferiu o poder absoluto de fixar as alíquotas do ICMS, sem observar princípios e necessidades constitucionalmente defendidas.

Tamanha é a discussão acerca do tema e a preocupação com a garantia das necessidades básicas da sociedade que Carrazza considerou que tanto o IPI quanto o ICMS devem ser utilizados como instrumentos de extrafiscalidade e estimular os contribuintes à utilização de meios mais benéficos à sociedade, quando do exercício de suas atividades. ${ }^{47}$

Destarte, cumpre apontar que, muito embora o dispositivo legal apresente como facultativa a aplicação do princípio da seletividade nos casos de tributação pelo ICMS, considera-se que a mesma deverá ocorrer em prol das garantias do mínimo existencial e da dignidade da pessoa humana.

\footnotetext{
${ }^{45}$ O referido dispositivo assim leciona: "III - poderá ser seletivo, em função da essencialidade das mercadorias e dos serviços; [...]”.

${ }^{46}$ PAULSEN, Leandro; MELO, José Eduardo Soares de. Op. cit. p. 264.

${ }^{47}$ CARRAZZA, Roque Antonio. Op. cit., 2006b. p. 95-97.
} 
Avançando no tema em questão, pode-se apontar que as alíquotas para a tributação pelo ICMS se dividem em dois grandes grupos: $1 .^{\circ}$ ) operações interestaduais; e $2 .^{\circ}$ ) operações internas.

No primeiro caso, conforme a Resolução do Senado n. ${ }^{\circ}$ 22, de 1989, as alíquotas são de $12 \%$ nas operações destinadas a contribuintes localizados nos Estados de Minas Gerais, Rio de Janeiro, São Paulo, Santa Catarina e Rio Grande do Sul, e de 7\% quando destinadas a contribuintes situados dos demais Estados da Federação. ${ }^{48}$

No segundo caso - operações internas -, as alíquotas são assim determinadas: a) 17\% é a alíquota básica, a qual se aplica às operações que não possuem alíquota específica; b) $12 \%$ é a alíquota reduzida, a qual se aplica às mercadorias consideradas mais essenciais, como, por exemplo, os produtos integrantes da cesta básica de alimentos, tijolos, fornecimento de refeições, etc.; e c) $25 \%$ é a alíquota majorada, aplicada a produtos supérfluos, tais como cigarros, bebidas, armas, perfumaria e cosméticos, bem como aos serviços de telecomunicações e energia elétrica. ${ }^{49}$

Dessa forma, salvo variações específicas, as alíquotas do ICMS sobre operações interestaduais são de sete ou 12\% e, nas operações internas, de 12, 17 ou 25\%.

Entretanto, da mesma forma como ocorre no IPI, porém de maneira mais precária, as alíquotas do ICMS somente obedecem ao princípio da seletividade nos casos de necessidade vital da sociedade. Em nenhum momento há a variação de alíquotas em conformidade com os danos ambientais que a mercadoria ou o serviço transportado podem causar ao meio ambiente.

Ainda, ressalta-se que, nas operações interestaduais, nem a seletividade é atendida, uma vez que são fixadas duas alíquotas, variando tão somente em função do ente federado destinatário.

Portanto, observa-se que o ICMS não possui nenhum método de variação de alíquota em função dos critérios de sustentabilidade. A pouca utilização da seletividade neste tributo somente se manifesta quando se fala em alíquotas internas, e, mesmo assim, as mercadorias e os serviços somente são classificados em face dos critérios de alimentação, vestuário,

\footnotetext{
${ }^{48}$ BRASIL. Resolução do Senado Federal no 22, de 19 de maio de 1989. Estabelece alíquota do imposto sobre operações relativas a circulação de mercadorias e sobre prestação de serviços de transporte interestadual e intermunicipal e de comunicação, nas operações e prestações interestaduais. Diário Oficial da União, Brasília, 22 mai. 1989, p. 7221.

${ }^{49}$ PAULSEN, Leandro; MELO, José Eduardo Soares de. Op. cit. p. 254-255.
} 
transportes, etc., ou seja, fundamentos básicos e frágeis para determinar as reais necessidades humanas.

Cristalino é que os referidos critérios são essenciais à sobrevivência, entretanto outros tantos critérios devem ser observados, como é o caso da sustentabilidade das mercadorias e dos serviços utilizados, o que, atualmente, não ocorre no ordenamento jurídico brasileiro.

\subsection{ICMS Ecológico}

Muito embora não se trate de espécie tributária, o ICMS ecológico é uma prática amplamente adotada entre os Estados e deve ser, ao menos, referida no presente trabalho, com o escopo de ressaltar a preocupação ambiental presente entre os entes federados.

Conforme determina o artigo 158, IV, da Constituição Federal, 25\% do produto da arrecadação do ICMS deverá ser creditado aos municípios. ${ }^{50}$ Deste percentual, conforme determinam os incisos do parágrafo único do mesmo dispositivo legal, três quartos deverão ser creditados segundo o critério de valor adicionado e um quarto, conforme dispuser lei estadual. $^{51}$

Valendo-se deste menor percentual que a legislação conferiu, os Estados vêm criando uma nova política perante os municípios, balizando o repasse financeiro do referido montante através de parâmetros notadamente ambientais.

Os valores e os critérios, legalmente estabelecidos, passaram então a ser quantificados diante de dados fáticos, gerando, com isso, um ranking ecológico dos municípios. Através do referido instrumento, o Estado arrecadador pode verificar o comprometimento dos entes municipais com o meio ambiente, e, quanto maior for seu compromisso ambiental, maior será a verba por esses percebida. Portanto, trata-se da adoção de critérios ambientalmente relevantes para a repartição das receitas normalmente obtidas.

Assim, observa-se que o referido instituto visa a estimular os municípios a preservar o meio ambiente, seja confrontando os poluidores, seja reservando espaços para a preservação

\footnotetext{
${ }^{50}$ O referido dispositivo assim determina: "IV - vinte e cinco por cento do produto da arrecadação do imposto do Estado sobre operações relativas à circulação de mercadorias e sobre prestações de serviços de transporte interestadual e intermunicipal e de comunicação”.

51 Os referidos dispositivos assim lecionam: "Parágrafo único. As parcelas de receita pertencentes aos Municípios, mencionadas no inciso IV, serão creditadas conforme os seguintes critérios: I - três quartos, no mínimo, na proporção do valor adicionado nas operações relativas à circulação de mercadorias e nas prestações de serviços, realizadas em seus territórios; II - até um quarto, de acordo com o que dispuser lei estadual ou, no caso dos Territórios, lei federal”.
} 
ambiental. Nota-se que os critérios de avaliação para a distribuição da renda devem ser estabelecidos em lei estadual, em face do disposto no artigo 158, parágrafo único, II, da Constituição Federal.

Por conseguinte, o referido instituto corrobora plenamente o objetivo do estudo em tela, uma vez que visa a um tratamento diferenciado àqueles municípios preocupados com a saúde ambiental.

Observa-se que esta iniciativa já é aplicada em grande parte do país, incluindo os Estados do Paraná (pioneiro a adotar o ICMS ecológico), Acre, Amapá, Ceará, Mato Grosso, Mato Grosso do Sul, Minas Gerais, Pernambuco, Piaú́, Rio de Janeiro, Rio Grande do Sul, Rondônia, São Paulo e Tocantins. ${ }^{52}$

\section{PROPOSTA VALORATIVA DA TRIBUTAÇÃO AMBIENTAL}

Conforme amplamente abordado no transcorrer do presente trabalho, necessário é que os produtos ecologicamente corretos recebam tratamento diferenciado, em face da função relevantemente social que possuem.

Infere apontar que, além do direito fundamental de o ser humano não ser privado de sua vida e dispor de todos os meios apropriados de subsistência e de padrão de vida decente, o direito à vida engloba, também, a garantia de um meio ambiente equilibrado, que, inclusive, é observado e assegurado pela Constituição Federal em seus artigos 170, VI, e $225 .{ }^{53}$ Logo, não se trata de uma busca inerente aos interesses sociais, mas de uma total afinidade com os mesmos.

Nesta seara, busca-se uma maneira de, através do Direito Tributário, realizar o direito a um meio ambiente ecologicamente equilibrado, o que se faz através de uma tributação “ecológica”.

Ricardo Carneiro muito bem aponta que os tributos ambientais podem realizar os objetivos da tutela protetiva do meio ambiente de três maneiras distintas: $1 .^{\circ}$ ) podem ser utilizados como incentivos aos produtores e aos consumidores finais, resultando na readequação de seus processos, comportamentos e hábitos com vistas a uma utilização mais eficiente e equilibrada dos insumos naturais e dos produtos oriundos; $2 .^{\circ}$ ) os tributos ambientais também podem originar as receitas necessárias aos cofres públicos, as quais

\footnotetext{
${ }^{52}$ ABREU, Rafaela Franco. Op. cit. p. 243.

${ }^{53}$ VIEIRA, Andréia Costa. Op. cit. p. 18-19.
} 
poderiam fomentar os projetos de melhoria da qualidade ambiental, permitindo, ainda, a desoneração progressiva dos encargos incidentes sobre o trabalho e sobre o capital; e, $3 .^{\circ}$ ) os tributos podem construir mecanismos eficientes para o controle de proliferação de fontes não estacionárias ou difusas de poluição. ${ }^{54}$

Assim, consoante análise realizada por Carneiro, pode-se concluir que a tributação ambiental, mais do que mera forma de arrecadação do estado, é eficiente meio para a realização de diversos fins sociais, entre eles a busca por um meio ambiente sustentável.

Neste sentido, considera-se que a utilização do critério ambiental, como baliza do princípio da seletividade, traria ao Direito brasileiro enorme ganho, pois, de um lado, aumentaria a arrecadação de tributos, diante da tributação agressiva aos produtos, mercadorias e serviços poluentes, e, de outro lado, auxiliaria de forma imprescindível a busca por um meio ambiente saudável.

Desta forma, pretende-se que a valoração do princípio da seletividade observe critérios ecológicos a serem desenvolvidos pela união das forças ambientais e jurídicas, adequando, assim, a tributação aos valores buscados pela sociedade.

Cumpre reiterar que, seja na criação de novas incidências tributárias, seja na diferença de graduação imposta à carga tributária, privilegiando atividades "limpas” ou onerando produções de consumos poluentes, o que está em causa não é apenas - ou propriamente - a arrecadação fiscal, mas a "finalidade” de promover a "defesa do meio ambiente". 55

Portanto, plenamente plausível é a observação do princípio da seletividade pelos valores ambientais, fortalecendo, com isso, a defesa ao meio ambiente e proporcionando à humanidade uma vida relevantemente mais salutar.

Destarte, analisa-se que, mesclando as funções fiscais e extrafiscais da tributação ambiental, a lei tributária possuiria plenas condições para fazer a distinção entre poluidores e não poluidores. Assim, premiaria os contribuintes que colaborassem com a preservação ambiental, orientando-os, assim, quanto à promoção do equilíbrio ecológico. ${ }^{56}$

\section{CONSIDERAÇÕES FINAIS}

Embora se tenha chegado ao final da presente exposição, muito ainda há de se falar acerca da matéria proposta. Aponta-se que o presente trabalho não objetivou o esgotamento

\footnotetext{
${ }^{54}$ CARNEIRO, Ricardo. Direito Ambiental: uma abordagem econômica. Rio de Janeiro: Forense, 2003. p. 80.

55 OLIVEIRA, José Marcos Domingues. Direito Tributário e Meio Ambiente: proporcionalidade tipicidade aberta, afetação da receita. Rio de Janeiro: Forense, 1995. p. 39.

${ }^{56}$ Ibidem, p. 28.
} 
sobre o tema posto em debate, mas sim uma reflexão sobre o assunto, buscando apresentar as possíveis soluções para a concretização, pelas vias do Direito Tributário, da prerrogativa constitucional a um meio ambiente ecologicamente equilibrado.

Para tanto, através do primeiro capítulo, buscou-se realizar breve análise histórica dos movimentos globais em prol da defesa do meio ambiente, bem como sua evolução. Ainda, demonstrou-se a presença da referida preocupação no ordenamento jurídico brasileiro, disposta nos artigos 170, VI, e 225 da Constituição Federal.

Posteriormente, passou-se à análise do Direito Comparado, buscando apresentar como a matéria se comporta no exterior. Ainda, fez-se análise conceitual da extrafiscalidade tributária e do princípio da seletividade, demonstrando a possibilidade de os mesmos contribuírem para a concretização dos direitos supramencionados.

Depois, examinou-se a tributação ambiental no Direito brasileiro, buscando conceituála e verificar os meios possíveis para sua concretização. Constatou-se que, até o presente momento, inexiste legislação específica prevendo a sua utilização, no entanto, algumas práticas tributárias já são amplamente empregadas para a sua efetivação. Assim sendo, passou-se à investigação da presença da tributação ambiental no IPI e no ICMS.

Quanto ao IPI, observou-se que a seletividade se impõe plenamente, uma vez que a Constituição Federal, em seu artigo 153, § 3. ${ }^{\circ}$, I, assim determina. No entanto, nesses casos, a seletividade tem sido aplicada com observância exclusiva dos direitos à liberdade e de o ser humano possuir meios apropriados de subsistência e de padrão de vida decente. Nesta seara, não é tratado o direto ambiental como limitador da tributação seletiva do IPI, passando, portanto, distante deste tributo, o que não se demonstra cabível.

No que diz respeito ao ICMS, a situação é ainda mais grave, porque nesse tributo nem ao menos o princípio da seletividade é respeitado, sob a justificativa da "facultatividade" de sua aplicação, disposta no artigo 155, § 2. ${ }^{\circ}$, III, da Constituição Federal. Poucas são as variações de alíquotas no ICMS, principalmente nos casos de operações internas, mas em nenhum dos casos é observado o meio ambiente como valor necessário à obtenção de uma vida digna.

Desta forma, buscou-se relacionar o princípio da seletividade e a tutela por um meio ambiente saudável, objetivando sua aplicação efetiva através do IPI e do ICMS, o que conclui-se - é plenamente possível. Aponta-se que o direito buscado é item necessário a uma boa qualidade de vida e também valor almejado por toda a sociedade. 
Ressalta-se, ademais, que o direito a um meio ambiente sadio e ecologicamente equilibrado é verdadeiro prolongamento do direito de viver. E preservar o meio ambiente, em últimas palavras, quer dizer preservar a vida em todas as suas formas. ${ }^{57}$

Portanto, propõe-se uma valoração ecológica da seletividade tributária, utilizando como baliza a contribuição do produto, da mercadoria e do serviço, para a obtenção de um meio ambiente ecologicamente correto. Assim, concretizar-se-iam os princípios da dignidade humana e do mínimo existencial, ofertando aos cidadãos melhor qualidade de vida, fator necessário a uma existência honrada.

\section{REFERENCIAS}

ABREU, Rafaela Franco. A tributação ambiental no Brasil e nos Estados Unidos - Uma análise comparativa. Publicações da Escola da AGU, Brasília, v. 4, n. 16, p. 233-252, mar. 2012.

AMARAL, Paulo Henrique. Direito Tributário Ambiental. São Paulo: Revista dos Tribunais, 2007. 240 p.

ARAÚJO, Luiz Ernani Bonesso de; BARICHELLO, Stefania Eugenia; TEIXEIRA, Michele Oliveira. Tributação ambiental: considerações sobre o ICMS ecológico e alguns tributos verdes de países desenvolvidos. Revista da Procuradoria-Geral do Estado, Porto Alegre, v. 31, n. 66, p. 135-151, jul./dez. 2007.

BALEEIRO, Aliomar. Direito Tributário brasileiro. 7 ed. Rio de Janeiro: Forense, 1975. 607 p.

BECKER, Alfredo Augusto. Teoria Geral do Direito Tributário. 2 ed. São Paulo: Saraiva, 1972. $621 \mathrm{p}$.

BOTTALLO, Eduardo Domingos. IPI: princípios e estrutura. São Paulo: Dialética, 2009. 208 p.

BRASIL. Código Tributário Nacional. Disponível em: <http://www.planalto.gov.br/ ccivil_03/leis/15172.htm>. Acesso em: 2 jun. 2013.

- Constituição da República Federativa do Brasil de 1988. Disponível em: <http://www.planalto.gov.br/ccivil_03/constituicao/constituicao.htm>. Acesso em: $1 .^{o}$ jun. 2013.

. Decreto Federal n. ${ }^{\text {755/93, de }} 19$ de fevereiro de 1993. Reduz as alíquotas do Imposto sobre Produtos Industrializados incidente sobre os veículos automotores que enumera. Diário Oficial da União, Brasília, 20 fev. 1993, p. 2272.

${ }^{57}$ RODRIGUEIRO, Daniela A; SOUZA, Luiz Gustavo Alves de. Op. cit. p. 345. 
. Resolução do Senado Federal n 22, de 19 de maio de 1989. Estabelece alíquota do imposto sobre operações relativas a circulação de mercadorias e sobre prestação de serviços de transporte interestadual e intermunicipal e de comunicação, nas operações e prestações interestaduais. Diário Oficial da União, Brasília, 22 mai. 1989, p. 7221.

CALIENDO, Paulo. Tributação e mercado de carbono. In: TORRES, Heleno Taveira (Org.). Direito Tributário Ambiental. São Paulo: Malheiros, 2005. p. 872-894.

CARBAJO VASCO, Domingo; HERRERA MOLINA, Pedro M. Marco conceptual, constitucional y comunitario de la fiscalidad ecológica. Revista de Direito Tributário, São Paulo: Malheiros, 2003. v. 89.

CARNEIRO, Ricardo. Direito Ambiental: uma abordagem econômica. Rio de Janeiro: Forense, 2003. 176 p.

CARRAZZA, Roque Antonio. Curso de Direito Constitucional Tributário. 22 ed. São Paulo: Malheiros, 2006a. 1041 p.

$\overline{1080 \mathrm{p} .}$

Curso de Direito Constitucional Tributário. 24 ed. São Paulo: Malheiros, 2006b.

; BOTTALLO, Eduardo Domingos. IPI, seletividade e alteração de alíquotas. Revista Dialética de Direito Tributário, São Paulo, RDDT, n. 159, p. 107-114, dez. 2008.

COSTA, Regina Helena. Tributação ambiental. In: FREITAS, Vladimir Passos de (Coord.). Direito ambiental em evolução. Curitiba: Juruá, 1998. v. 1. p. 297-309.

DANILEVICZ, Rosane Beatriz Jachimovski. O princípio da essencialidade na tributação. Direito tributário em questão. Revista da FESDT, Porto Alegre, v. 2, n. 3, p. 229245, jan./jun. 2009.

DIFINI, Luiz Felipe Silveira. Manual de Direito Tributário. 4 ed. atual. São Paulo: Saraiva, 2008. $378 \mathrm{p}$.

GUSMÃO, Omara Oliveira de. Proteção ambiental e tributação: O tributo como coadjuvante na concretização do valor constitucional "meio ambiente”. Revista Tributária e de Finanças Públicas, São Paulo, Revista dos Tribunais, n. 66, p. 113-148, jan./fev. 2006.

NABAIS, José Casalta. Direito Fiscal e Tutela do Ambiente em Portugal. In: TORRES, Heleno Taveira (Org.). Direito Tributário Ambiental. São Paulo: Malheiros, 2005. p. 412-444.

NOGUEIRA, Ruy Barbosa. Principio da seletividade do tributo em função da essencialidade do produto. São Paulo: Revista dos Tribunais, 1990. v. 651.

OLIVEIRA, José Marcos Domingues. Direito Tributário e Meio Ambiente: proporcionalidade tipicidade aberta, afetação da receita. Rio de Janeiro: Forense, 1995. 280 p.

PAULSEN, Leandro; MELO, José Eduardo Soares de. Impostos federais, estaduais e municipais. 4 ed. rev. e atual. Porto Alegre: Livraria do Advogado, 2008. 420 p. 
RODRIGUEIRO, Daniela A; SOUZA, Luiz Gustavo Alves de. Do caos à consciência ecológica: breves reflexões sobre degradação e preservação ambiental. Revista do Instituto de Pesquisas e Estudos, Bauru, Divisão Jurídica, n. 48, p. 337-350, jul. 2007.

TABOADA, Carlos Paolo. El principio “quien contamina paga” y el principio de capacidad económica. In: TORRES, Heleno Taveira (Org.). Direito Tributário Ambiental. São Paulo: Malheiros, 2005. p. 79-95.

TEIXEIRA, Dalvio Leite Dias; TEIXEIRA, Silvia Maria Benedetti. A constitucionalidade da tributação ambiental no Brasil. Revista da AJURIS, Porto Alegre, Associação dos Juízes do Rio Grande do Sul, v. 36, n. 115, p. 73-84, set. 2009.

TORRES, Heleno Taveira. (Org.). Direito Tributário Ambiental. São Paulo: Malheiros, 2005. $894 \mathrm{p}$.

VIEIRA, Andréia Costa. O direito humano ao meio ambiente e a tributação ambiental: água e ar: mecanismos nacionais e internacionais. Fórum de Direito Urbano e Ambiental, Belo Horizonte, v. 9, n. 53, p. 18-26, set. /out. 2010. 